\title{
Analisa Web untuk Memahami Perilaku Konsumen Online Studi Kasus "Store Steam Powered"
}

\author{
Endang Supriyadi \\ Institut Ilmu Sosial dan Manajemen STIAMI \\ endangs2013@gmail.com
}

\begin{abstract}
Abstrak. Perkembangan pengguna internet dari tahun ketahun hingga saat ini terus meningkat, hal tersebut dapat diketahui melalui survey yang dilakukan Internet Worldstats. Menurut survey yang dilakukan oleh Internet Worldstats, United Stated menempati urutan ke-3 dari pengguna internet sedunia setelah negara Cina. Dari hasil survey tersebut menunjukkan bahwa hampir seluruh kegiatan/aktifitas bisnis yang dilakukan oleh penduduk dunia dan khususnya penduduk United State / Amerika menggunakan fasilitas internet dalam segala aktifitasnya terutama transaksi secara online. Dan salah satu tool yang dapat membantu untuk menganalisa perilaku konsumen online yaitu dengan menggunakan web analytics. Tujuan dari makalah ini adalah untuk menganalisis bagaimana data analisis dapat secara efektif digunakan untuk memahami perilaku konsumen online saat ini. Diharapkan dengan penggunaan analisis web, perusahaan dapat memprediksi perilaku konsumen online masa depan dan pesan khusus terhadap promosi-promosi yang telah dikirim ke masing-masing individu. Dengan memahami pola dan hal-hal yang terdapat pada web analisis diharapkan dapat membantu untuk mengembangkan proses bisnis dan isi serta disain yang perlu dibuat khususnya "store steam powered". Store steam powered merupakan salah satu distributor digital game milik Valve yang berbasis web. Pelayanan utama yang dilakukan adalah penjualan steam game melalui sebuah web e-commerce yang bertujuan untuk menghindari pembajakan yang sangat marak pada saat ini.
\end{abstract}

Kata Kunci : web analytics, store steam powered, perilaku konsumen online.

Abstract. The development of internet users from year to year to date continues to increase, it can be known through a survey conducted Internet Worldstats. According to a survey conducted by Internet Worldstats, United Stated ranks 2nd of internet users worldwide after China. From the results of the survey shows that almost all activities / business activities undertaken by the world population and in particular the citizens of United State / America using internet facilities in all activities, especially transactions online. And one of the tools that can help to analyze online consumer behavior is by using web analytics. The purpose of this paper is to analyze how data analysis can be effectively used to understand current consumer behavior online. Expected with the use of web analytics, companies can predict future consumer behavior online and special messages on promotions that have been sent to each individual. Understanding the patterns and things on the web analytics is expected to help to develop business processes and the contents and design that need to be made especially "store steam powered". Store steam powered is one of Valve's webbased digital distributor. The main service that is done is steam game sales through an e-commerce web that aims to avoid piracy is very rampant at the moment.

keywords : web analytics, store steam powered, Online consumer behavior. 


\section{PENDAHULUAN}

\section{A. Perkembangan Pengguna Internet \& Gamer}

Teknologi saat ini yang paling cepat berkembang adalah teknologi telekomunikasi dan teknologi informasi. Perkembangan ini sangat terlihat akselerasinya dalam kehidupan, dan hampir setiap sisi kehidupan kita selalu merasakan manfaat adanya perkembangan teknologi informasi dan telekomunikasi tersebut. Perkembangan tersebut akan menumbuhkan pula bisnis di bidangnya, sebagai contoh adalah internet dan komputer. Setiap perkembangan teknologi akan mendukung munculnya teknologi baru, atau fasilitas baru dalam suatu produk tersebut. Oleh karena itu maka produk-produk teknologi tersebut setiap saat akan naik dan terus meningkat jumlahnya.

Pengguna teknologi internet terus meningkat dari tahun ke tahun. Setidaknya itu terbukti dari data yang disajikan oleh hasil survey yang dilakukan Worldstat update tertanggal 31 maret 2017 (stats, 2017).

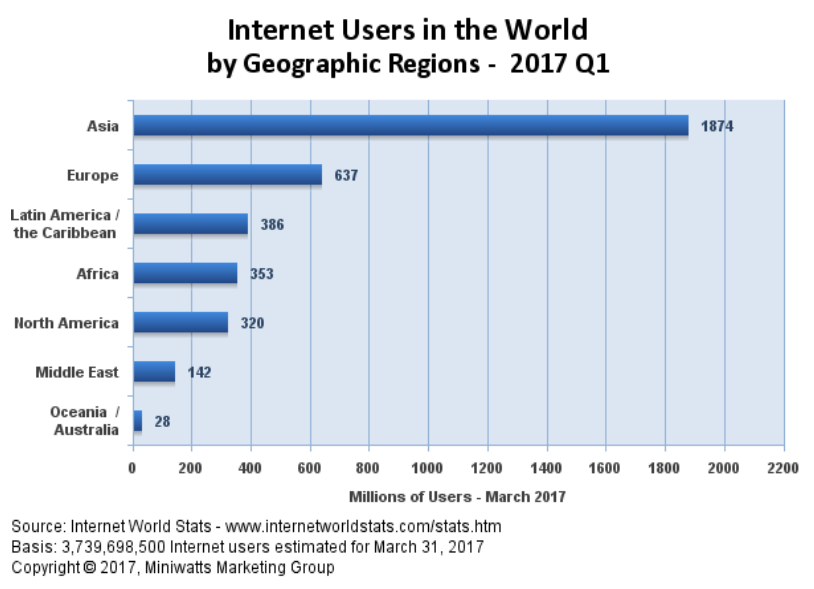

Gambar 1. Pengguna Internet di dunia tahun 2017

Dari grafik diatas dapat disimpulkan bahwa pengguna internet wilayah bagian Negara Asia di tahun 2017, sangat mendominasi dan mengalami peningkatan yaitu sebesar 1874 (juta) dari populasi penduduk dunia .

Dan US termasuk negara peringkat ke-3 setelah china. Gambar grafik berikut ini memperjelas kedudukan peringkat United States sebagai salah satu negara dari 20 pengguna internet terbanyak, sebagaimana yang terlihat pada gambar grafik berikut ini :

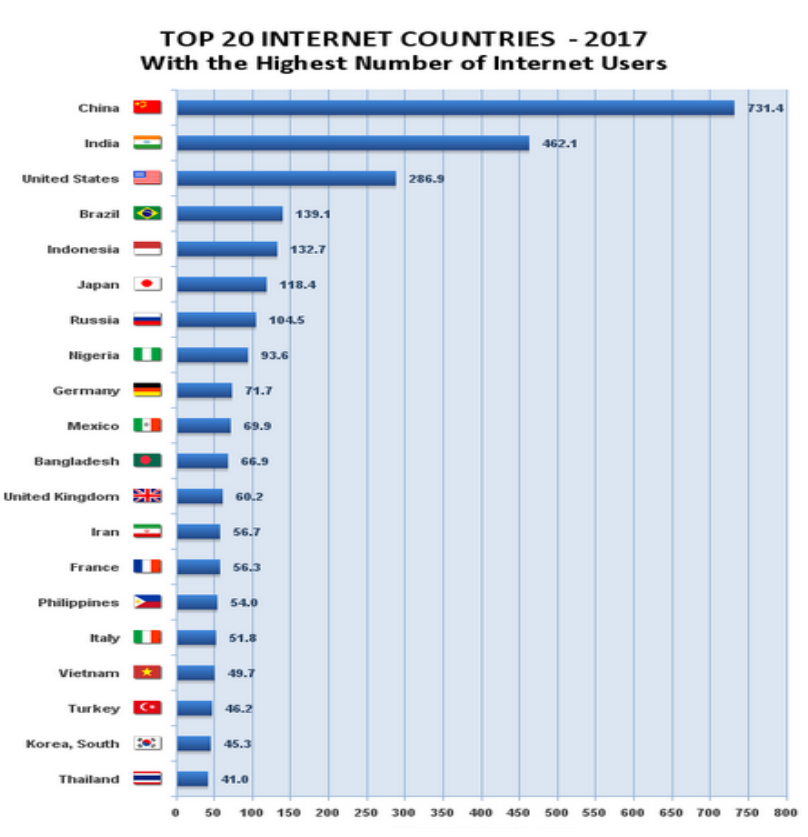

Gambar 2. Grafik Pengguna Internet terbanyak pada 20 negara (stats, 2017)

Sehingga dapat dipahami bahwa mayoritas penduduk US atau Amerika sudah tidak asing lagi menggunakan internet untuk melakukan pertukaran informasi seperti penyampaian iklan, hiburan dan transaksi penjualan kepada masyarakat, dsb. (Giddens, 2001). Melalui internet pula masyarakat dapat berkomunikasi secara langsung baik dengan satu orang dengan yang lainnya maupun dengan banyak orang seperti email, chating, forum/berdiskusi tentang suatu topik permasalahan yang sama, komentar/tanggapan tentang suatu produk yang ditawarkan oleh suatu perusahaan tertentu. Hal tersebut dapat dilakukan secara cepat dan biaya murah tanpa terhalang dengan ruang dan waktu (Suyasa, 2005). Bahkan hingga kini teknologi internet sudah dijadikan gaya hidup atau life Style bagi masyarakat dalam segala aktifitas kehidupannya. (effendi, 2010). Semua aktifitas seperti berkomunikasi dengan individu lainnya, berbelanja (shoping online), melakukan pekerjaan kantor dengan jarak jauh, menawarkan produk baik barang maupun jasa secara online, hal tersebut sangat mudah dilakukan dengan adanya media internet.

Penjual/Marketer dan pembeli/konsumen dapat saling berinteraksi untuk bertransaksi secara online melalui website yang merupakan display produk yang ditawarkan. 
Endang Supriyadi, Analisa Web untuk Memahami Perilaku Konsumen Online ....

Dan salah satu tool yang dapat membantu untuk menganalisa perilaku konsumen online yaitu dengan menggunakan web analytics.

Seperti yang dikemukan oleh Wei Fang : Web analytics is the measurement, collection, analysis and reporting of internet data for the purposes of understanding and optimizing web usage (Fang, 2007). Dan menurut Kaushik : Web analytics is the objective tracking, collection, measurement, reporting, and analysis of quantitative internet data to optimize websites and web marketing initiatives (Kaushik, 2007).

\section{B. Indentifikasi Masalah}

Analisis web merupakan tools yang digunakan untuk mengetahui perilaku konsumen online terhadap suatu produk yang ditawarkan oleh marketer. Namun tidak semua website yang ada didunia maya menggunakan analisis web, padahal dari hasil survey yang dilakukan oleh sebuah situs yang bernama http://w3techs.com (w3techs, 2017), telah tercatat sampai dengan saat ini (1 Juni 2017) sekitar $54,3 \%$ dari semua website yang ada menggunakan web analytic khususnya google analytics.

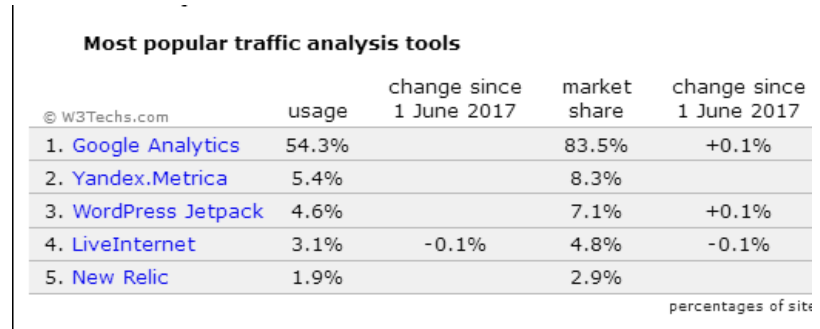

Gambar 3. Tools Analilsis Terpopuler

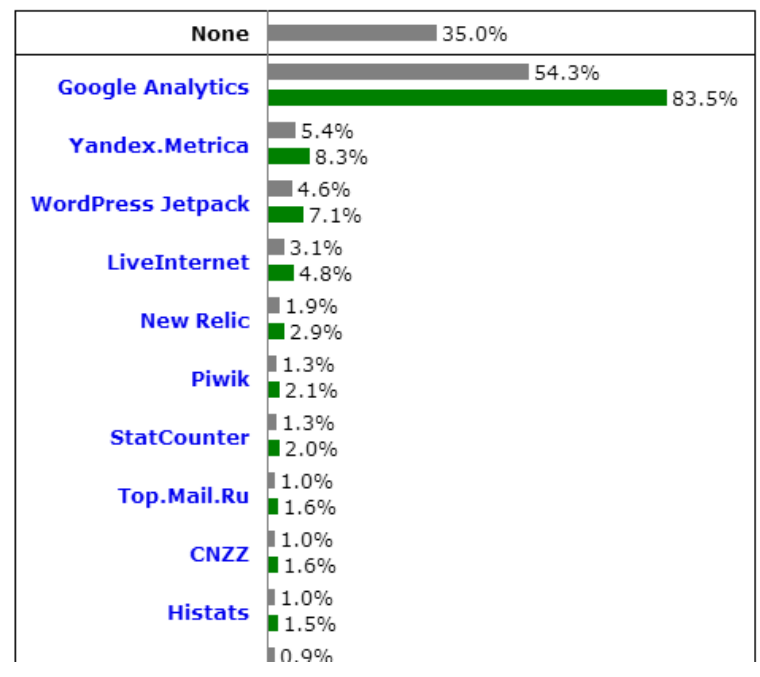

Gambar 4. Penggunaan Tools Analisis situs web

C. Ruang Lingkup

Adapun batasan masalah dalam penulisan ini adalah sebagai berikut :

1. Menganalisa trafik visitor website khususnya "Store Steam Powered" .

2. Analisis web menggunakan salah satu tools yaitu : google analytics.

D. Tujuan \& Manfaat

1. Tujuan dari penulisan jurnal ini adalah:

a. Memahami perilaku konsumen Store Steam Powered menggunakan google analytics tools.

b. Mengetahui secara mendalam penggunaan /fungsi feature yang terkandung dalam google analytics.

c. Diharapkan dengan penggunaan google analytics tools, perusahaan dapat memprediksi perilaku konsumen online masa depan dan pesan khusus terhadap promosipromosi yang telah dikirim ke masing-masing individu.

2. Manfaat dari penulisan jurnal ini adalah:

a. Dengan mengetahui perilaku konsumen, pemilik website dapat menyimpulkan kebutuhan yang diharapkan oleh konsumennya dan strategi bisnis apa yang harus dilakukan.

b. Dengan menggunakan google analytics diharapakan dapat meningkat revenue perusahaan.

c. Dapat diimplementasikan pada website lainnya selain "Store Steam Powered".

d. Menimbulkan kesadaran yang tinggi tentang besarnya manfaat yang dihasilkan dari penggunaan google analytics bagi pengembang/developer web.

\section{TINJAUAN PUSTAKA}

\section{A. Perilaku Konsumen online}

Menurut (Engel, 1993) perilaku konsumen pada dasarnya merupakan tindakan tindakan individu yang secara langsung terlibat dalam usahamemperoleh,mengkonsumsidanmenghabis 
kanproduk atau jasa termasuk didalamnya proses pengambilan keputusanendahului dan mengikuti tindakan yang mendahului dan mengikuti tindakan-tindakan tersebut. Dan Menurut (Wilkie, 1990) Perilaku konsumen adalah kegiatan yang dilakukan orang saat memilih, membeli, dan menggunakan produk dan layanan sehingga dapat memenuhi kebutuhan dan keinginan. Kegiatan semacam itu melibatkan proses mental dan emosional, selain tindakan fisik.

Sehingga dapat disimpulkan bahwa perilaku konsumen online adalah tindakan-tindakan yang dilakukan oleh individu, kelompok atau organisasi yang berhubungan dengan proses pengambilan keputusan dalam mendapatkan barang melalui media online.

B. Alat Analisis Web (Web analytic tools)

Ada berbagai macam alat analisis selain google analytic yang dapat digunakan untuk menganalisa perilaku konsumen terhadap produk yang ditawarkan oleh marketer diantaranya (w3funtion, 2017):

1. Clicky, tools ini lebih fokus dalam analisis secara realtime, tersedia data historis, dan juga disediakan pula detil twitter analisis yang dapat membantu untuk mengukur dampak media social terhadap suatu website.

2. Woopra, memungkinkan dapat melihat pengunjung online dan berinteraksi dengan para pengunjung/visitor melalui widget obrolan woopra. Fitur lainnya yang dimiliki oleh woopra adalah memungkin developer untuk mengatur beberapa jenis pemberitahuan baik berupa email maupun popup berdasarkan tindakan dan situasi yang berbeda.

3. Chartbeat, menyediakan analisis secara realtime bagi penerbit berita dan bagi developer yang sedang membangun layanan untuk situs e-commerce. Pada tools ini tersedia metrik yang unik yang dapat melihat pengunjung berinteraksi dengan situs dan mengidentfikasikan area untuk perbaikan.

4. Gosquared, menyediakan semua jenis standard metric, juga memungkinkan melihat data khusus pengunjung individu. Tools ini terintegrasi dengan layanan chat secara langsung dengan konsumen online( Olark). Tools ini juga dapat diatur agar tampil peringatan pada saat ada lonjakan atau penurunan visitor secara mendadak.

5. Mixpanel, memungkinkan marketer dapat melihat visitor dapat terlibat dalam website, mengamati tren, dan membandingkan metrik dari titik sebelumnya dalam kurun waktu. Serta tersedia ekstensif segmentasi dan saluran fitur analisis.

6. Histats, memiliki fitur online visitor (recent, most active visitor, popular pages, popular referer, geolocation), free $100 \%$, menampung traffic stats hingga lebih dari 10 tahun, menyimpan url, judul halaman/tag yang telah dikunjungi jejak download/click, stats dan tren (hitstat feature, 2017).

7. Piwik, merupakan tools web analisis open source untuk analisis realtime. Piwik dapat diinstal pada suatu server dan memiliki 48 bahasa dunia.

8. Shiny stat, memiliki empat produk yang berbeda termasuk produk yang sangat terbatas, analisis untuk website pribadi dan non-profit. Dan juga mencakup deteksi peringkat search engine untuk membantu melacak dan meningkatkan website.

9. Seevolution, dengan tools ini marketer dapat melihat fitur heatmaps dan realtime analisis overlay pada websitenya. Juga tersedia cara unik untuk melihat data analisis tanpa meninggalkan situs anda.

10. Statcounter, merupakan salah satu layanan analisis gratis yang dapat diinstal hanya dengan beberapa baris kode. Ini mencakup semua data analisis yang khas, juga dapat mengatur laporan email otomatis yang akan dikirim harian, mingguan atau bulanan. 


\section{Metode Penelitian}

Metodologi yang digunakan dalam penelitian ini untuk menganalisa perilaku konsumen online yaitu menggunakan salah satu tools terpopuler saat ini yaitu menggunakan google analytics yang terintegrasi pada situs www.steampowerd.com.

\section{A. Statistik Web di Google Analytics}

Analisis web merupakan salah satu cara yang dapat digunakan untuk mengatur performance / kinerja suatu web / situs. Karena secara umum analisis web selalu menyertakan adanya layanan laporan secara realtime baik perhari, perminggu, maupun perbulan sehingga dapat membantu marketer/pengembang web untuk memantau efektifitas strategi webnya secara keseluruhan (Zara, 2012).

Salah satu tool yang banyak diminati oleh pengembang web/marketer adalah google analytic, hal ini terbukti dari hasil survey yang telah dilakukan oleh salah situs yang bernama : http://w3techs.com telah mencatat sebanyak 49,8 $\%$ dari semua situs yang ada pada saat itu menggunakan google analytic.

\section{B. Definisi Google Analitics}

Google Analytics merupakan sebuah tool yang dimilki oleh Google untuk menganalisa website. Web Analytics ini bersifat gratis tetapi memiliki fitur yang tidak kalah menarik dengan web analytics yang berbayar.

1. Fitur google analytic terdiri dari (google, 2107) :

a. Alat Analisis, google analytic menyediakan laporan standard yang memudahkan untuk mengukur dan memahami keterlibatan suatu situs dan juga dapat dengan cepat membuat laporan khusus, segmen pengunjung, dan mengindentifikasikan data penting yang sangat dibutuhkan.

b. Analisis Konten, google dapat menyajikan konten/isi informasi yang terpopuler atau isi situs yang paling sering dikunjungi visitor, seberapa lama berada disitus tersebut dan seberapa sering mereka berkonversi.

c. Analisis Seluler, google analytics menyediakan alat untuk mengukur situs seluler, aplikasi dan kunjungan dari perangkat seluler yang berfitur web, termasuk ponsel kelas atas dan biasa serta tablet.

d. Paket konversi, sarana ini digunakan untuk membantu marketer/pengembang agar mereka mengetahui lebih dari sekedar tayangan laman dan jumlah pengunjung. Melainkan juga dapat mengukur penjualan, unduhan pemutaran video, dan tindakan lainnya yang bernilai positif sehingga lebih memahami keinginan pengunjung untuk membeli produk dengan alasan tertentu. Dengan demikian marketer dapat mengambil suatu keputusan yang tepat dengan menyesuaikan keinginan pengunjung.

e. Laporan Sosial, laporan ini dapat membantu untuk mengukur dampak media sosial yang ditimbulkan terhadap tujuan dan konversi bisnis yang sudah ditetapkan.

f. Analisis Periklanan,google analytics menyediakan analisis periklanan dengan maksud agar marketer atau pengembang dapat menganalisa apakah iklan yang telah diprogramkan berhasil atau tidak, hal tersebut dapat dilakukan dengan cara menggunakan saluran digital berupa penelusuran, display, social, affiliasi, dan email dan juga mengintegrasikannya dengan AdWords. 
TRANSPARANSI

Jurnal Ilmiah Ilmu Administrasi

ISSN 2085-1162

2. Alur Pembuatan Akun pada Google Analytics

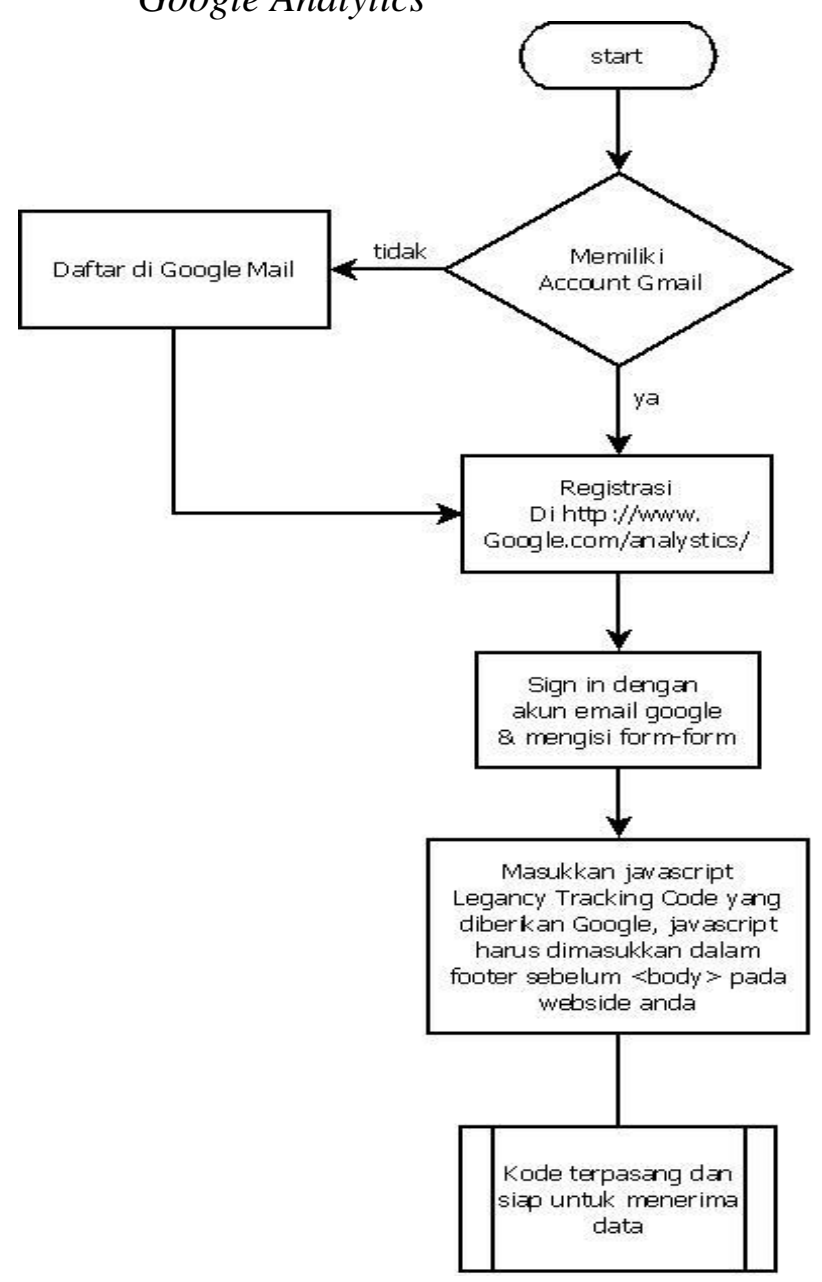

Gambar 5. Alur Pembuatan Akun Google Analitycs

(Syahrial, 2010)

IV. Hasil dan Pembahasan

\section{A. Konsolidasi Store Steam Powered dengan Web analisis Steam.}

Berikut ini akan dijelaskan secara rinci penggunaan web analisis yang telah dikembangkan sendiri oleh pihak developer Valve untuk mengetahui kondisi statistik terhadap konsumen online. Namun sebelunnya akan dijelaskan gambaran secara umum mengenai store steam power.

\section{Sekilas Tentang Store Steam Powered}

Store Steam Powered merupakan salah satu toko online dengan core bisnis penjualan digital permainan/games yang terkenal milik Valve diantara produknya adalah steamwork. Steamwork adalah sistem proteksi game-game baru, cara kerjanya adalah pada saat
Volume VII, Nomor 02, September 2015

penginstalan game harus sudah terkoneksi dengan internet karena sebelum software/aplikasi game diinstall akan ditanyakan identitas dan password steam, setelah diverifikasi oleh steam maka aplikasi game dapat melanjutkan penginstalannya hingga selesai. Sedangkan system pembelian dilakukan dengan cara pengunduhan terlebih dahulu steam selanjutnya konsumen dapat melakukan pembayaran via online sesuai dengan aplikasi game yang diinginkan. Dengan adanya system ini pembajakan terhadap software terutama aplikasi games dari berbagai macam categori dapat ditekan (steam, 2017).

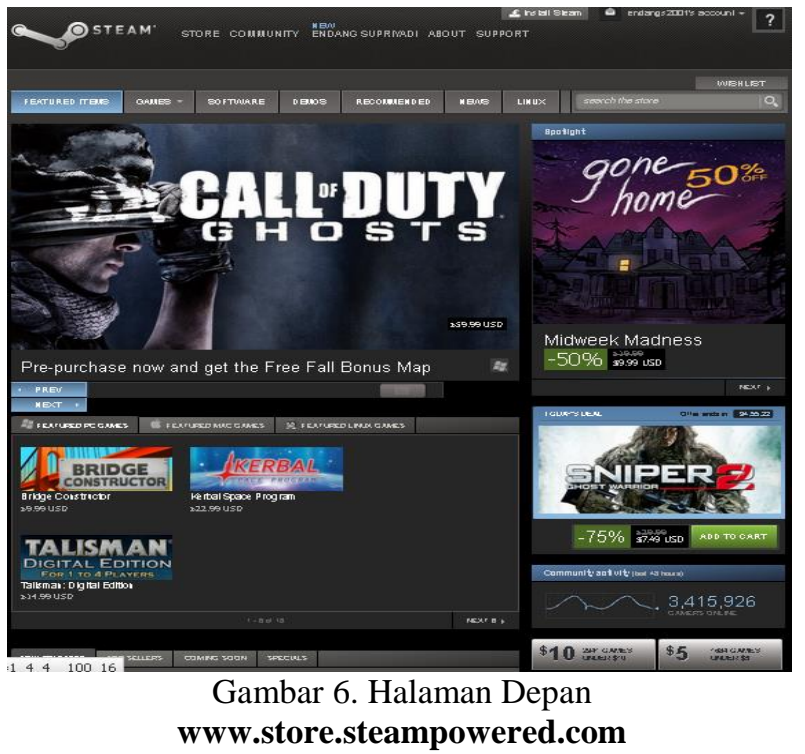

2. Analisa perilaku konsumen store steam powered periode april-september 2013.

a. Statistik Aktifitas Konsumen

Pada website ini developer Valve sengaja menempatkan media surveynya pada halaman depan, agar calon pelanggan dapat mengetahui secara online pengunjung yang telah registrasi dan menjadi calon pembeli serta pelanggan tetapnya. Sehingga dengan demikian memicu ketertarikan konsumen lain untuk membeli produk yang diinginkan. Selain itu konsumen dapat mengetahui trend aplikasi game yang sedang populer atau aplikasi game yang banyak diminati oleh konsumen pada saat itu. Sehingga dengan demikian konsumen dapat memutuskan untuk membeli game yang sedang populer dan dapat mengikuti 
Endang Supriyadi, Analisa Web untuk Memahami Perilaku Konsumen Online ....

perkembangan zaman. Seperti yang terlihat pada gambar berikut ini :

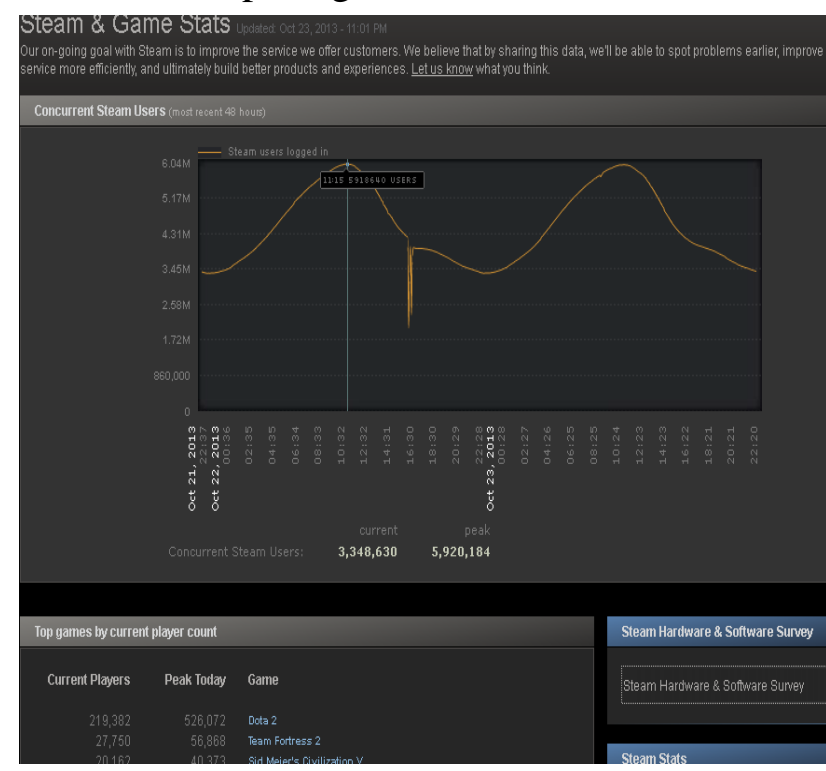

Gambar 5. Detail Aktifitas Konsumen

\section{b. Statistik Pengunaan Hardware \&} Software

\section{$\checkmark$ VGA / PC Video Card}

Selain menggambarkan hasil survey jumlah konsumen yang sedang online dan game yang sedang hit / populer. Situs ini juga menyediakan hasil survey hardware \& Software yang digunakan pengguna game, seperti yang terlihat gambar berikut ini :

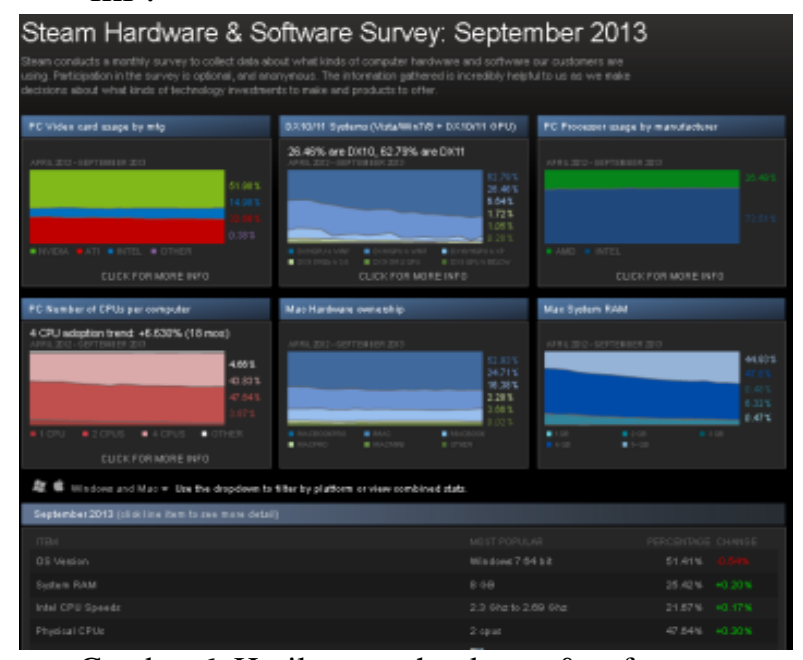

Gambar 6. Hasil survey hardware \& software

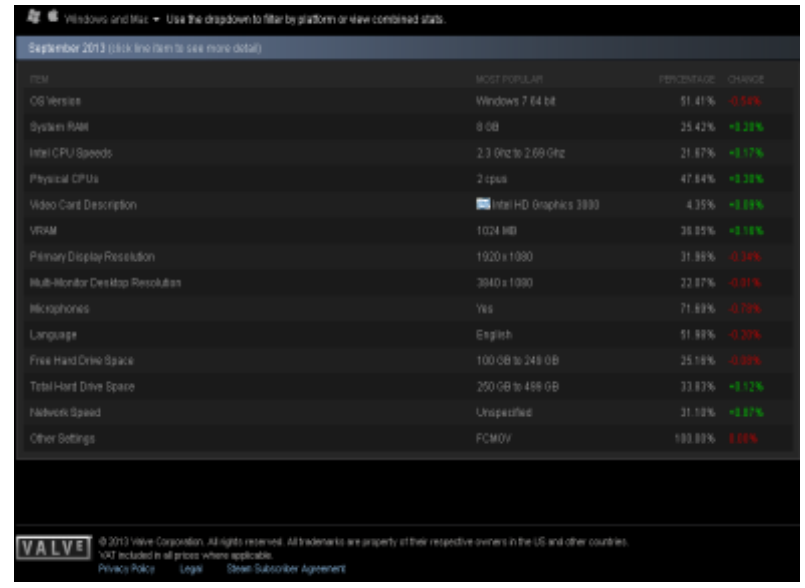

Gambar 7. Detail survey hardware \& software

Dari hasil survey grafik pada gambar 6 menginformasikan bahwa pengguna mayoritas menggunakan vga nvidia ( $51,98 \%$ ) . Karena kecendrungan pengguna game/gamer mayoritas menggunakan dual core dengan hasil survey yaitu sebanyak 47,64\%.

\section{$\checkmark$ Sistem Operasi}

Sedangkan sistem operasi yang digunakan lebih banyak para gamer menggunakan window 764 bit dan compatible dengan direct x 3D 11, yaitu sebesar $62,79 \%$ karena saat ini game yang diproduksi oleh 5 produsen game yang terkenal seperti xbox 360, ea games, sony playstation, zinga games networks, rockstar game lebih banyak memproduksi game 3D.

\section{$\checkmark$ PC Processor}

Penggunaan prosessor lebih didominasi oleh Intel, dengan hasil survey sebanyak $73,51 \%$ dan dengan kecepatan sebesar 2,3 Ghz sampai dengan 2,69 Ghz dengan hasil survey sebesar 21,67\%. Karena intel lebih mendominasi dengan brand marketnya dan terlebih dahulu terlahir dibandingkan dengan AMD. Kinerja / perfomance processor berada diperingkat atas. Amd lebih boros listrik, lebih cepat panas. Terlebih lagi durasi waktu untuk memainkan game cukup lama sehingga membutuhkan perfomance vga yang tinggi dan kesetabilan prosesor. 
TRANSPARANSI

Jurnal Ilmiah Ilmu Administrasi

ISSN 2085-1162

\section{RAM/Memory}

Memori / ram yang digunakan mayoritas pengguna game sebesar $8 \mathrm{gb}$ untuk mendukung akselerasi data yang diperlukan sebab data yang ditampilkan lebih didominasi oleh gambar / grafis maka kapasitas memori yang dibutuhkan juga besar sebagaimana dengan hasil survey menghasilkan sebanyak $25,42 \%$.

\section{$\checkmark$ Resolusi Monitor}

Resolusi monitor mayoritas menggunakan 1920X1080, hasil survey sebesar $31,96 \%$. hal ini membuktikan agar game yang dijual / dipasarkan memenuhi resolusi gambar yang diinginkan.

\section{$\checkmark$ Harddisk}

Total harddisk yang dibutuhkan adalah sebesar $250 \mathrm{gb} \mathrm{s} / \mathrm{d} 499 \mathrm{gb}$, hasil survey menghasilkan 33,83\%. Kapasitas yang besar sangat mendukung untuk menyimpan semua data-data yang diperlukan tidak hanya satu game saja melainkan lebih dari itu. Pada saat ini kapasitas harddisk untuk instalasi dan menampung data yang diperlukan adalah sebesar $100 \mathrm{gb}$ s/d $249 \mathrm{gb}$, dengan hasil survey sebesar $25,16 \%$.

c. Penggunaan Bandwith

Penggunaan bandwith yang telah dikonsumsi oleh konsumen steam powered lingkup seluruh negara untuk mendownload aplikasi steam, seperti gambar berikut ini :

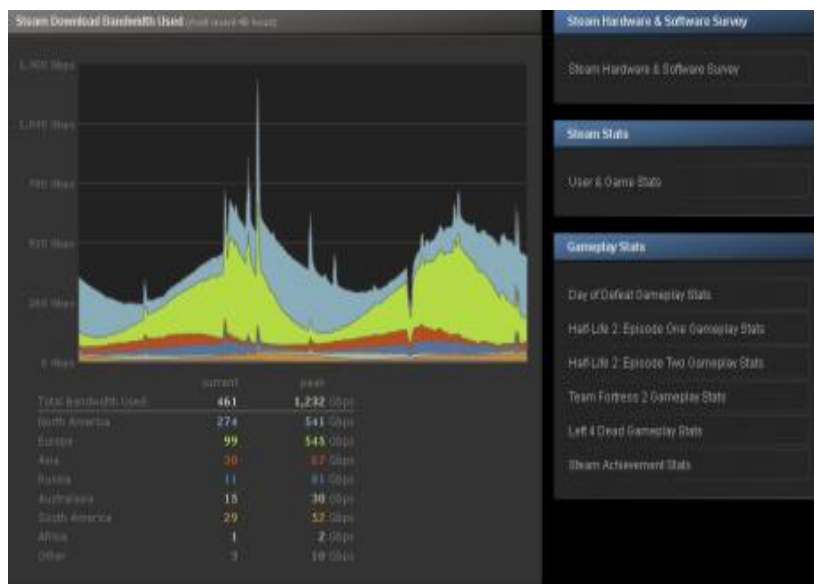

Gambar 8. Hasil survey penggunaan bandwith
Volume VII, Nomor 02, September 2015

Dari gambar 8 tersebut menunjukkan bahwa penggunaan bandwith didominasi oleh negara pembuat/pengembang aplikasi ini yaitu Amerika Serikat khususnya Amerika Utara, dengan hasil survey sebesar 541 gbps (tertinggi) dan hingga saat ini sebesar 274 gbps. Sehingga dengan demikian mayoritas konsumen dari steam powered adalah Amerika Serikat.

d. Statistik aktifitas gamer (gameplay)

Berikut ini kondisi statistik aktifitas yang dilakukan gamer/konsumen dengan mangambil salah satu sampel game dengan tema left 4 dead, sebagaimana yang terlihat pada gambar berikut ini :

Gambar 9. Hasil survey aktifitas gamer tema : left 4 dead

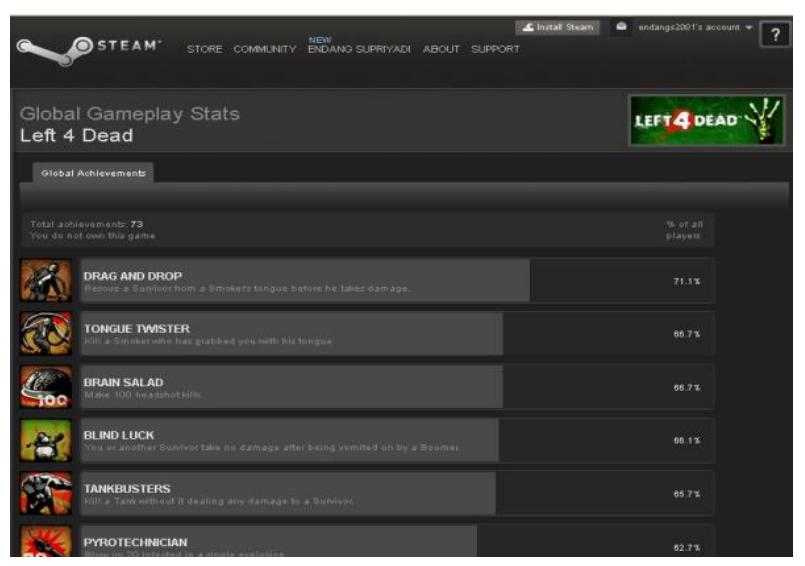

Dari gambar 9 terlihat bahwa hasil survey secara umum yang tertinggi dari pencapaian penggunaan aksi yang dimiliki oleh drag and drop (tindakan penyelamatan yang dilakukan pemain terhadap salah satu survivor dari ancaman kematian lidah smoker) adalah sebesar $71,1 \%$. Dari data ini diketahui bahwa mayoritas pemain/ gamer lebih menguasai penggunaan aksi drag and drop.

Dengan mengetahui penggunaan sumber daya harddisk dan software diharapkan pihak pemasar / marketer dapat menyediakan software / aplikasi game yang dijual sesuai dengan kebutuhan yang diinginkan konsumen selaras dengan hardware dan software yang paling banyak digunakan. Selain itu juga pihak pemasar/marketer juga harus memperhatikan faktor lainnya seperti 
Endang Supriyadi, Analisa Web untuk Memahami Perilaku Konsumen Online ....

penggunaan bandwith yang menjadi penunjang untuk mendownload aplikasi steam yang merupakan control panel dari masing komunitas/member dan sekaligus konsumen steam powered.

\section{Kesimpulan \& Saran}

\section{A. Kesimpulan}

1. Web analisis merupakan salah satu tools yang digunakan untuk mengukur secara statistik kondisi perkembangan trafik pengunjung/konsumen agar marketer/pihak pengelola web dapat mencari strategi bisnis baru yang sesuai dengan keinginan konsumennya.

2. Store steam powered menyediakan Web analisis yang sengaja dibuat sendiri untuk kebutuhan survey mereka sehingga dengan demikian pengunjung dapat mengetahui secara rinci dan jelas jumlah statistik user, game yang banyak diminati, penggunaan hardware \& software, bandwith serta aktifitas game play. Hal tersebut dimaksudkan agar menarik pengunjung baru dapat bergabung dan membuat keputusan membeli produk yang ditawarkan store steam powered.

3. Konsumen store steam powered hanya didominasi oleh penduduk US dan kurang mendapat respon dari negara lain. Sehingga diperlukan strategi bisnis baru atau promosi iklan agar dapat memperluas pangsa pasar seluruh negara.

4. Dengan menggunakan pelayanan menggunakan steam powered pembajakan software dapat dikurangi.

\section{B. Saran}

1. Perlu dikembangkan strategi bisnis baru untuk mengembangka pangsa pasar baru di negara lainnya selain Amerika Serikat.

2. Perlu penyesuaian harga games dengan kondisi perekonomian negara lain.
3. Penyediaan sarana untuk mempercepat akses store steam powered lebih diperhatikan.

4. Harapan penulis bagi pengelola web ecommerce dapat mengadaptasikan web store steam powered dengan web ecommerce Indonesia dengan demikian dapat menekan pembajakan software umumnya dan software game khususnya.

\section{Bibliography}

(n.d.).

effendi. (2010). Peranan Internet Sebagai Media Komunikasi. Komunika (Jurnal Dakwah dan Komunikasi), Vol. IV, No. 1.

Engel, J. B. (1993). Consumer Behavior. USA: The Dryden Press.

Fang, W. (2007). Using google analytics for improving library website content and design : a case study. Journal Philosopy, 2.

Giddens, A. (2001). An Introduction to Sociology. London: W. W. Norton, Incorporated.

google. (2107, 7 31). Retrieved from Fitur google analytics: https://www.google.com/intl/id_ALL/analy tics/features/index.html

hitstat feature. (2017, 7 31). Retrieved from hitstat.com: http://www.histats.com/?act=2

Kaushik, A. (2007). Web Analytics:An Hour a Day. United States: Jhon Willey \& Sons.

stats. (2012, Juni). Retrieved from worldstats: http://www.internetworldstats.com/stats. htm

stats. (2017). Retrieved from internet world stats.

steam. (2017). Retrieved from steampowered: http://id.wikipedia.org/wiki/steam 
Jurnal Ilmiah Ilmu Administrasi

ISSN 2085-1162

steampowered. (2017). Retrieved from

http://store.steampowered.com

Suyasa, P. T. (2005). Perbedaan Minat dalam

Penggunaan Fungsi Internet berdasarkan

Tipe Kepribadian. Jurnal Psikologi, Vol. 3,

No. 2.

Syahrial, K. M. (2010, Oktober 1). Analisa Statistik Pengunjung Situs Resmi Universitas Syiah Kuala (www.Unsyiah.ac.id). Oktober, pp. Vol. 9 , No. 2.

w3funtion. (2017, 7 31). Retrieved from Google Analityc dan Alternatif Pilihan layanan Website Analityc lainnya: http://www.w3function.com/blog/index.p $h p ? p=\operatorname{det} \& i d n=65$,

w3techs. (2017, 6 1). Usage of Traffic Analysis Tools for Websites. Retrieved from w3techs.com : web technology surveys:

https://w3techs.com/technologies/overvie w/traffic_analysis/all

Wilkie, W. L. (1990). Consumer Behavior 2nd Edition. Canada: John Willey \& Sons Inc.

Zara, J.-A. B. (2012). Using Analytics for Understanding The Customer Online. Romania: Bucharest. 
Endang Supriyadi, Analisa Web untuk Memahami Perilaku Konsumen Online .... 